\section{Nutrition is key to global pandemic resilience}

\author{
Bryndis Eva Birgisdottir
}

Healthful food of good quality is our first line of defence against diseases, ${ }^{1}$ including immune defences against pathogenic organisms. ${ }^{23}$ In the current worldwide concern of coronavirus SARS-CoV-2, resulting in the COVID-19 disease, a sturdy immune system is considered central. ${ }^{4}$ This inevitably puts focus on the saga of the harmonious concert between nutrition and the immune system, unfolding over the last century. ${ }^{2}$

Big pandemics and resourceful pathogens have shaken the world before, with devastating death tolls of often young people, such as through the Spanish influenza and tuberculosis. ${ }^{56}$ Although biological processes or mechanisms were less understood at the time, it was simply considered common sense that those who had access to enough quality food had a better chance against diseases. Later, or mid-century, the extended and cyclical relations between malnutrition and infections were elegantly described, ${ }^{2}$ and diabetes was also early identified as a condition making people especially vulnerable to pathogens. ${ }^{7}$

\section{AN INTERWOVEN WORLD}

Today, however, the increasing diversity of reliable quality tools that are available to assess immune function have facilitated the remarkable increases in our comprehension of the design of both the innate and adaptive immune system. ${ }^{2}$ Scientific advances have also brought with them an emerging understanding of the web of genes, the immune system and nutritional status, including energy metabolism and the gut microbiota, although many puzzles still remain to be solved. ${ }^{38}$ The current challenge is to capture the complexity of this multidimensional relationship, interacting via

Correspondence to Dr Bryndis Eva Birgisdottir, Unit for Nutrition Research, Faculty of Food Science and Nutrition and Landspitali-University Hospital, Haskoli Islands, Reykjavik, Iceland; beb@hi.is multiple direct and indirect pathways, ${ }^{3}$ while at the same time tracing and understanding the effect of single nutrients of special importance. ${ }^{910}$

As the immune system develops and forms from conception to adulthood, ${ }^{3}$ a natural decline in immune function is usually inevitable with age. ${ }^{4}$ However, this decline may be slowed through optimal nutrition, as well as optimisation of other lifestyle factors such as physical activity and sedentariness, stressors and sleep, throughout the life course. ${ }^{9}$ All are of great importance. However, when facing communicable diseases, nutritional status is undoubtedly one of the firm basic modules of fitness. This is discussed from different viewpoints in the papers by Derbyshire and Delange, Calder, Kohlmeier, Lanham-New et al, Mossink, McAuliffe and colleagues, ${ }^{41-15}$ which are part of a still growing collection of papers published in the BMJ Nutrition, Prevention and Health, on nutrition and the fight against pathognes, sparked by COVID-19. The collection aligns with the mission of the journal, which is to present the best available evidence of the impact of nutrition and lifestyle factors on the health of individuals and populations.

\section{VAST AMOUNT OF COMPOUNDS}

Each meal brings thousands of different substances into the body, affecting thousands of different biological processes, all the way to the cellular and subcellular level. Scientists are only beginning to grasp this enormous universe of food and nutrition effects on the body. Among these substances are nutrients, both macronutrients and micronutrients for which reference daily intakes have been defined, as well as upper levels for safe intake for many. ${ }^{16} 17$ However, a plethora of other bioactive substances found in foods, such as polyphenols and carotenioids, that seem to be important for health and wellness, are also brought along. The importance of these are bluntly reflected in food-based dietary guidelines (FBDGs), represented as recommendations for a variety and diversity of whole vegetables, fruits, berries, nuts, seeds, grains and pulses, along with some meats, eggs, dairy products and fish, if selected, as discussed in the paper by Calder. ${ }^{4}$ This type of healthy diet is a tactical aproach to build a healthy body and a strong immune system, as emphasised by the WHO and other organisations during the pandemic, ${ }^{18}$ especially when eaten at the expense of more ultraprocessed food items. ${ }^{19}$

\section{NUTRITION IS A BALANCING ACT}

Furthermore, the diet described previously would for most people provide ample amount of the micronutrients that have been suggested to be of special importance for the immune system. ${ }^{4}$ However, vitamin D as one of the key micronutrients for the immune system has been given special focus by several papers in the collection. ${ }^{12} 13$ The vitamin is found in only an handful of foods and populations with low sun exposure have been found to be prone to low status, especially during the winter months. To ensure adequate vitamin D status, such as through guideline-directed supplementation, while also taking into account special conditions and common risk variants such as skin colour and even obesity is of high value. Optimal nutrition is a balancing act and adequate amounts of nutrients acting in concert are essential, while too little or too much has different consequences, depending on the nutrient, as put forward in the current collection, relating especially to zinc, with another paper focusing on micronutrients. $^{14} 15$ It must, however, be emphasised, that there is no such a thing as an average person. ${ }^{20}$ Public health goals will always be approximations for what is optimal for some groups, while each group member has specific needs for energy, nutrients and bioactive substances, depending on many different factors. Over time, these key factors will be used increasingly as part of Precision Nutrition to make nutrition guidance more effective throughout the life cycle, ${ }^{20}$ including better understanding of vulnerable groups, such as 
men in the current pandemic, but also disease states, genetic traits, microflora, pollution, stress and infections. With more focus on Precision Nutrition, this information will feed into public health nutrition recommendations which, given the speed of publication, need to be under constant review.

\section{SPECIAL CONDITIONS: CLINICAL SETTING}

However, with advancing age and for high-risk groups, a nutrient-rich diet is not always enough to meet needs for micronutrients. ${ }^{4} 14$ While high intakes should be avoided, there may be a a role for immune-targeted supplements that might be necessary to achieve the intake of nutrients needed for an optimally functioning immune system. ${ }^{4}$ Furthermore, there is one thing to enhance the public health nutritional status, through preventive actions, while the clinical situation of an active disease is another situation altogether. Overall, older people are harder hit, and while fighting an infection, the nutrient needs of patients might be increased. ${ }^{14}$ This might warrant special nutrition therapy, potentially with higher doses or cocktails of supplements and functional foods, $^{11}$ as quality care also involves quality nutritional care. Recently, the European Society for Clinical Nutrition and Metabolism issued guidelines for nutritional managaement of COVID-19 due to increased cases of malnutrition in COVD-19. ${ }^{21}$ Recent case studies have also laid bare the importance of specialised nutritional treatment in critically ill patients with COVID-19. ${ }^{22}$

\section{A NUTRITION ODYSSEY}

Together, the papers in the current collection and additional related ones in the journal shed light on the importance of food and nutrients, but also on the importance of more research in the field of nutrition and immune system. Sound large-scale studies are urgently needed. Given our current knowledge and given the nature of nutrition, it is clear that a simplistic approach for understanding is not enough. We need both reductionistic and wholistic scientific approaches to fully understand nutrition ${ }^{23}$ as trusted knowledge reveals itself slowly in this field of science. ${ }^{20}$ This means, for example, looking at the same problem from many different viewpoints, with a narrowly targeted perspective or looking at an array of foods and compounds, but also through different prisms of groups over time and patterns and data-driven analytical techniques. As a sophisticated science, it thus needs a multitude of methods that can highlight the multidimensional aspects of the same research question. ${ }^{24}$ Not least to be able to tackle myths and hypes around diet and nutrition, non-needed supplements and other special products. ${ }^{11}$ Sometimes, diets or supplements have simply not been properly investigated, and their actions not sufficiently understood, while others are more clearly indefensible and may cause harm. The science of nutrition is an evolving a saga in progress, futuristic in parts, developing with time, as new focus points and research tecniques come to light. We now know more about individuality in responses, which seem to differ substantially between people for whole diets, specific foods and single nutrients, ${ }^{25}$ and high metabolic flexibility seems a strength. Furthermore, it has even been suggested that a single optimal nutrition pattern may not be possible, as a different nutritional state might be optimal in different circumstances. ${ }^{3}$ Nutrition is thus a challenging field, ${ }^{13}$ which is part of its charm. However, using the dietary guidelines for food and nutrients as starting point for public health nutrition actions is sound, as they are to be built on the best available scientific evidence at each moment in time.

\section{THE WORLD IS MALNOURISHED}

However, general populations mostly do not follow the guidelines, ${ }^{4}$ for many different reasons. It has been estimated that at least $44 \%$ of the world population is suffering from malnutrition, ${ }^{26}$ either due to undernutrition (lack of energy and/or nutrients) and overnutrition (too much energy and/or nutrients, eg, overconsumption of supplements), with both conditions a risk factor for the disease and severity of disease, as the COVID-19 pandemic has revealed. ${ }^{27}$ This double burden of malnutrition ${ }^{126}$ can be found within the same countries but also within the same families and even in the same individuals. It is therefore important to investigate to what degree suboptimal intake of immune-related nutrients might be associated with the variation in immune outcomes/disease outcomes seen in different areas. ${ }^{4} 13$ Generally, it should be part of a healthy lifestyle strategy of every country to ensure that populations are in good nutritional status. ${ }^{26}$ The habitual focus points of underweight and overweight are only two out of a number of many important nutrition-related factors to consider.

MONITORING NUTRITIONAL STATUS: THE LIFE ENGINE OF A POPULATION Optimal public health nutrition would then be to monitor the nutrional status of the world's populations more closely, with focus on special vulnerable groups throughout the life cycle, including measures of immune status. This should currently be a priority of every nation to then actively use this knowledge base for targeted actions, relating to food systems and food security as reflected in another BMJ Nutrition Prevention and Health collection. ${ }^{28}$ Our diet has changed massively over the last 100 years and it is bound to change massively again over the next few decades. Both due to the environmental challenges we are facing, where current food production is one of the major players ${ }^{1}$ and due to technological progresses made in food production where food is made in laboratories. This makes monitoring nutritional status an even more important public health issue of the future. Being attentive to the food and nutritional needs of the population, even only special important nutrients, can lead to enormous profits, both in the form of less expenses and in better health and wellness of the population. Optimal nutritional status is not only important to increase resilience against communicable diseases but also the same actions are likely to increase resilience to non-communicable diseases as well, both physical and mental disorders.

\section{FOOD ENVIRONMENTS ARE} IMPORTANT FOR IMMUNE SYSTEMS However, it is not enough to look only at the microscopic entities inside the 
body to deal with the current problem. We need to investigate the macroscopic forces affecting the body from the outside. Food is vital for our existence and being able to meet our nutritional needs is a human right. ${ }^{29}$ This is best demonstrated by the simple fact that the only legitimate reason to get out of lockdown in many countries has been to get food. Food security has thus been at the core of the pandemic, although policy makers are often not attentive to the importance of quality food for our health. Our food stores are therefore full of products that are unhealthy for our bodies in the amount they are eaten. Healthy nutrient-rich food is then hidden in between these products like in a wierd game of hide and seek. These highly abnormal circumstances when shopping for food have been normalised and go hand in hand with relentless advertisement of the same products. Instead of decision makers focusing on making the healthy choice, the easy choice, the public is left in constant fight with the food environment, which is then entangled with equity and poverty as well. ${ }^{3031}$ Considering how much we know about the devastating effect of unhealthy food and the forces that guide our choices everyday, it is strange to see so many countries sacrifice the health of their nations on the altar of raw capitalism. Not least as one of the foremost responsibilities of a government is to protect its population. ${ }^{32}$ In the end, it comes down to people themselves, but the environment should not make it harder to adhere to a healthy diet. On a public health scale, even very small changes in nutritional status, for example, of vitamin $D$, can lead to immense benefits for official budgets, public health and wellness of many people.

\section{POLICIES AND ACTION PLANS AS SUPERFICIAL ORNAMENTS}

Despite beautiful public health nutrition policies that are in place in many countries, through governmental agencies and numerous associations, they are not taken seriously ${ }^{13}$ with no budget or small budgets allocated to do the actual design and implementation of action plans. This needs to change as we already have the knowledge to tackle different nutritional challenges through many different approaches in different societies, often with clear focus on the determinants that affect our food intake. These are often described as intrapersonal factors, that is, things that are within a person's reach to change or not; interpersonal factors, that is, more relating to social circumstances but also community settings, including the built food environment and then food and nutrition policies of all types and shapes. ${ }^{33}$ Public health nutrition interventions should consider each of these levels in their design while fitting their approach into a food system and food security perspective, as well as to use behavioural science to support changes in perception, knowledge and behaviour. ${ }^{34}$ We all love food; it is closely knit to our feelings and cultures. Experience has shown the significance of taking human habits and pleasure into account when making food policies, and action plans that contain both political and public commitment and resources.

\section{COMMUNICATING COMPLEXITY TO} THE PUBLIC AND POLICY MAKERS

The situation we are in today, however, is also a result of far too little nutrition education throughout the whole school system, which is a bit odd, given the importance of food for our being. Nutritional knowledge needs to be as prioritised and to be as evident as learning to read and write while also focusing on weaving nutritional knowledge into all types of other education settings. Novel nutrition education is needed now, to educate future public health nutrition leaders as well as other health workers with a nonnutritional background to get a deeper understanding of food and the proper skills and toolsets to work with the public. ${ }^{20}$ This is the focus of another important collection of papers in BMJ Nutrition, Prevention and Health. ${ }^{35}$ As nutrition is vastly important for everyone on earth, increasing nutrition literacy along with nutritional science literacy of the public, is a worthy goal. We need to be able to communicate the complexity of nutrition, while at the same time upholding the importance of a healthy diet from a public health nutrition viewpoint, defined by the best scientific knowledge at each point in time.

\section{HUMANITARIAN CRISIS ON THE HORIZON}

It is now clear that there is a global food crisis on the horizon in the aftermath of COVID-19, and it is most likely to affect the most vulnerable populations the most, with foreseen long-term physical and cognitive consequences. ${ }^{36}$ It has been estimated that the current pandemic could almost double the number of people suffering from acute hunger. This needs to be fought by all means necessary. As pointed out in still another collection series in BMJ Nutrition, Prevention and Health, our global food systems are already in serious need of a sustainable and nutritional overhaul, ${ }^{37}$ mirrored in the association of food and nutrition with all the United Nations Sustainable Development Goals. ${ }^{38}$ Funding of bold and inspiring actions is urgently needed to revamp food systems to a more sustainable and nutrition-based focus.

It must be said out loud that many of us have been schooled to have a narrow perspective. Today, we need people of action that challenge the current thinking to embrace systemic thinking. ${ }^{39} 40$ This is not only for specialists; everyone can take part, for example, by inviting people in your community to nutrition saloons to discuss what can be done and building a bridge to different fields, as every person is a mind ready to grow. ${ }^{41}$ What is needed the most is moral courage and leadership and for everyone to perceive what they have to give, to do the hard things while spreading meaning and purpose. It seems clear from the data available that nutrition is one of the keys to global pandemic resilience, both for the current and future pandemics and could reduce burdens on healthcare systems. ${ }^{11}$ Optimal nutritional status is a defence against both communicable and non-communicable diseases. It is also something that can be attended to right now and is not months away. We are ecological creatures at a crossroad ${ }^{42}-$ let this pandemic be your wakeup call.

Contributors BEB is the author of this paper. 
Funding The authors have not declared a specific grant for this research from any funding agency in the public, commercial or not-for-profit sectors.

Competing interests No, there are no competing interests.

Patient consent for publication Not required.

Provenance and peer review Commissioned; externally peer reviewed.

\section{() OPEN ACCESS}

Open Access This is an open access article distributed in accordance with the Creative Commons Attribution Non Commercial (CC BY-NC 4.0) license, which permits others to distribute, remix, adapt, build upon this work non-commercially, and license their derivative works on different terms, provided the original work is properly cited, appropriate credit is given, any changes made indicated, and the use is non-commercial. See: http://creativecommons.org/ licenses/by-nc/4.0/.

C Author(s) (or their employer(s)) 2020. Re-use permitted under CC BY-NC. No commercial re-use. See rights and permissions. Published by BMJ.

\section{Check for updates}

To cite Birgisdottir BE. Nutrition is key to global pandemic resilience. BMJ Nutrition, Prevention \& Health 2020;3:e000160. doi:10.1136/ bminph-2020-000160

Received 27 August 2020

Accepted 31 August 2020

Published Online First 14 October 2020

bmjnph 2020;3:e000160.

doi:10.1136/bmjnph-2020-000160

ORCID iD

Bryndis Eva Birgisdottir http://orcid.org/ 0000-0002-5788-4551

\section{REFERENCES}

1 FAO, IFAD, UNICEF, WFP and WHO. In brief to the state of food security and nutrition in the world 2020. transforming food systems for affordable healthy diets. Rome: FAO, 2020.

2 Keusch GT. The history of nutrition: malnutrition, infection and immunity. J Nutr 2003;133:336S-40.

3 Ponton F, Wilson K, Cotter SC, et al. Nutritional immunology: a multi-dimensional approach. PLoS Pathog 2011;7:e1002223.

4 Calder PC. Nutrition, immunity and COVID-19. BMJ Nutr Prev Health 2020;3:74-92.

5 Huremović D. Brief History of Pandemics (Pandemics Throughout History). In: H
D, ed. Psychiatry of pandemics: a mental health response to infection outbreak, 2019: 7-35.

6 Stead WW. The origin and erratic global spread of tuberculosis: how thee past explains the present and is the keey to the future. Clinics in Chest Medicinee 1997;18:65-77.

7 Lönnroth K, Jaramillo E, Williams BG, et al. Drivers of tuberculosis epidemics: the role of risk factors and social determinants. Soc Sci Med 2009;68:2240-6.

8 Wolowczuk I, Verwaerde C, Viltart O, et al. Feeding our immune system: impact on metabolism. Clin Dev Immunol 2008;2008:1-19.

9 Zapatera B, Prados A, Gómez-Martínez S, et al. Immunonutrition: methodology and applications. Nutr Hosp 2015;31 Suppl 3:145-54.

10 Maggini S, Pierre A, Calder PC. Immune function and micronutrient requirements change over the life course. Nutrients 2018;10. doi:10.3390/nu10101531

11 Derbyshire E, Delange J. COVID-19: is there a role for immunonutrition, particularly in the over 65s? BMJ Nutr Prev Health 2020;3:100-5.

12 Lanham-New SA, Webb AR, Cashman KD, et al. Vitamin D and SARS-CoV-2 virus/ COVID-19 disease. BMJ Nutr Prev Health 2020;3:106-10.

13 Kohlmeier M. Avoidance of vitamin D deficiency to slow the COVID-19 pandemic. BMJ Nutr Prev Health 2020;3:67-73.

14 McAuliffe S, Ray S, Fallon E, et al. Dietary micronutrients in the wake of COVID-19: an appraisal of evidence with a focus on high-risk groups and preventative healthcare. BMJ Nutr Prev Health 2020;3:93-9.

15 Mossink JP. Zinc as nutritional intervention and prevention measure for COVID-19 disease. BMJ Nutr Prev Health 2020;3:111-7.

16 Nordic Nutrition Recommendations 2012. Integrating nutrition and physical activity. 5th edn. Copenhagen, Denmark: Nordic Council of Ministers, 2014.

17 Nutrition Support Team. Government dietary recommendations. government recommendations for energy and nutrients for males and females aged 1-18 yeaars and 19+ years. London, UK: Public Health England, 2016.

18 WHO. \#HealthyAtHome: Healthy Diet, 2020. Available: https://www.who.int/campaigns/ connecting-the-world-to-combatcoronavirus/healthyathome/healthyathomehealthy-diet

19 Elizabeth L, Machado P, Zinöcker M, et al. Ultra-Processed foods and health outcomes: a narrative review. Nutrients 2020;12. doi:10.3390/nu12071955. [Epub ahead of print: 30 Jun 2020].

20 Kohlmeier M. Nutrition is a hard science. BMJ Nutr Prev Health 2018:1:1-2.

21 Barazzoni R, Bischoff SC, Breda J, et al. ESPEN expert statements and practical guidance for nutritional management of individuals with SARS-CoV-2 infection. Clin Nutr 2020;39:1631-8.

22 Arkin N, Krishnan K, Chang MG, et al. Nutrition in critically ill patients with
COVID-19: challenges and special considerations. Clin Nutr 2020;39:2327-8.

23 Campbell TC. Nutritional renaissance and public health policy. J Nutr Biol 2017;3:124-38.

24 Simpson SJ, Le Couteur DG, James DE, et al. The geometric framework for nutrition as a tool in precision medicine. Nutr Healthy Aging 2017;4:217-26.

25 Dragsted LO. The metabolic nature of individuality. Nature Food 2020;1:327-8.

26 The global nutrition report, 2020.

27 Cuevas A, Barquera S. COVID-19, obesity and undernutrition: a major challenge for Latin American countries. Obesity 2020 (published Online First: 2020/07/09).

28 Johnsen JT, Buckner L, Ray S. Knowledge synthesis and translation in global food and nutrition security to evaluate and accelerate priority actions. BMJ Nutr Prev Health 2020;3:e000104.

29 About the right to food and human rights. M Fakhri. Special Rapporteur on the right to food, 2020. Available: https://www.ohchr. org/EN/Issues/Food/Pages/AboutHRFood. aspx

30 Moodie R, Stuckler D, Monteiro C, et al. Profits and pandemics: prevention of harmful effects of tobacco, alcohol, and ultra-processed food and drink industries. Lancet 2013;381:670-9.

31 Herman DR, Taylor Baer M, Adams E, et al. Life course perspective: evidence for the role of nutrition. Matern Child Health $\mathrm{J}$ 2014;18:450-61.

32 Frieden TR. Government's role in protecting health and safety. $N$ Engl J Med 2013;368:1857-9

33 Meltzer HM, Brantsæter AL, Trolle E, et al. Environmental sustainability perspectives of the Nordic diet. Nutrients 2019;11. doi:10.3390/nu11092248

34 Mozaffarian D, Rosenberg I, Uauy R History of modern nutrition scienceimplications for current research, dietary guidelines, and food policy. BMJ 2018;361:k2392.

35 Nowson C. Opportunities for innovation in nutrition education for health professionals. BMJ Nutr Prev Health 2020;3:123-5.

36 Laborde D, Martin W, Swinnen J, et al. COVID-19 risks to global food security. Science 2020;369:500-2.

37 Bradfield J, Trigueiro H, Ray S. Is global dietary change an effective strategy to curb climate change? BMJ Nutr Prev Health 2020;3:121-2.

38 FAO, IFAD, UNICEF, WFP and WHO. The state of food security and nutrition in the world 2018. Building climate resilience for food security and nutrition. Rome, Italy: FAO, 2018.

39 West GB. The importance of quantitative systemic thinking in medicine. Lancet 2012;379:1551-9.

40 Leischow SJ, Best A, Trochim WM, et al. Systems thinking to improve the public's health. Am J Prev Med 2008;35:S196-203.

41 Yeager DS, Hanselman P, Walton GM, et al. A national experiment reveals where a growth mindset improves achievement. Nature 2019;573:364-9.

42 Wahlqvist ML. Future food. Asia Pac J Clin Nutr 2016;25:706-15. 